\title{
A propósito de los Crucificados del escultor Jorge Fernández: una nueva atribución en el monasterio sevillano de Santa María de Jesús
}

\author{
José Roda Peña \\ Universidad de Sevilla \\ roda@us.es
}

RESUMEN: Este trabajo pretende ser un acercamiento al modelo iconográfico de Crucificado que tipificó el escultor Jorge Fernández en la Sevilla del primer tercio del siglo XVI, al tiempo que se da a conocer una nueva atribución suya, conservada en el monasterio hispalense de Santa María de Jesús.

PALABRAS CLAVE: Jorge Fernández; Crucificados; Escultura; Sevilla; Siglo XVI.

\section{About the Crucifixes of the Sculptor Jorge Fernández: a New Attribution in the Sevillian Monastery of Santa María de Jesús}

\begin{abstract}
This paper intends to be an approach to the iconographic model of the Crucifix that was typified by the sculptor Jorge Fernández in Seville during the first third of the $16^{\text {th }}$ century, while at the same time revealing a new attribution of his, preserved in the Sevillian monastery of Santa María de Jesús.
\end{abstract}

KEYWORDS: Jorge Fernández; Crucifixes; Sculpture; Seville; $16^{\text {th }}$ Century.

Recibido: 17 de noviembre de 2020 / Aceptado: 20 de marzo de 2021.

Desde el estado actual de nuestros conocimientos, Jorge Fernández (†1535), cuyo preciso lugar de origen sigue siendo una incógnita, se nos presenta como uno de los escultores más cualificados y prolíficos en la interpretación del Crucificado, tema primordial para la iconografía cristiana, en la Sevilla del primer tercio del siglo XVI. Procedente de Córdoba, donde había contraído matrimonio en 1504 con Constanza de Heredia, llegó a la capital hispalense cuatro años después para asentarse allí definitivamente y trabajar en la materialización del programa escultórico del retablo mayor de la catedral' . Tal circunstancia contribuyó decisivamente al encumbramiento de este escultor, situado al frente de un taller que desplegó una intensa actividad laboral, abarcando un mercado que desbordó con mucho los límites geográficos del antiguo reino de Sevilla, para alcanzar buena parte de Andalucía, el septentrión castellano de las Montañas de Burgos, el archipiélago canario y los virreinatos americanos. En la producción de este artífice, tanto en madera, como en piedra y barro, conviven en amigable maridaje estético los aires tardogóticos de su presumible formación junto a maestros de ascendencia nórdica, con cierta apertura a fórmulas de incipiente carácter renacentista².

En 1993, Fernando de la Villa y Esteban Mira dieron a conocer, de entre los que se conservan ${ }^{3}$, su primer Crucificado de autoría fehaciente, verdadera piedra de toque para muchas de las atribuciones que después se le han formulado de otras piezas de esta misma temática pasionista (1993: 7-13). Nos referimos al Cristo de la Amargura de Carmona, fechado en

Cómo citar este artículo: RODA PEÑA, José «A propósito de los Crucificados del escultor Jorge Fernández: una nueva atribución en el monasterio sevillano de Santa María de Jesús", Boletín de Arte-UMA, n. ${ }^{\circ}$ 42, Departamento de Historia del Arte, Universidad de Málaga, 2021, pp. 73-81, ISSN: 0211-8483, e-ISSN: 2695-415X, DOI: http:// dx.doi.org/10.24310/BoLArte.2021.vi42.10783 


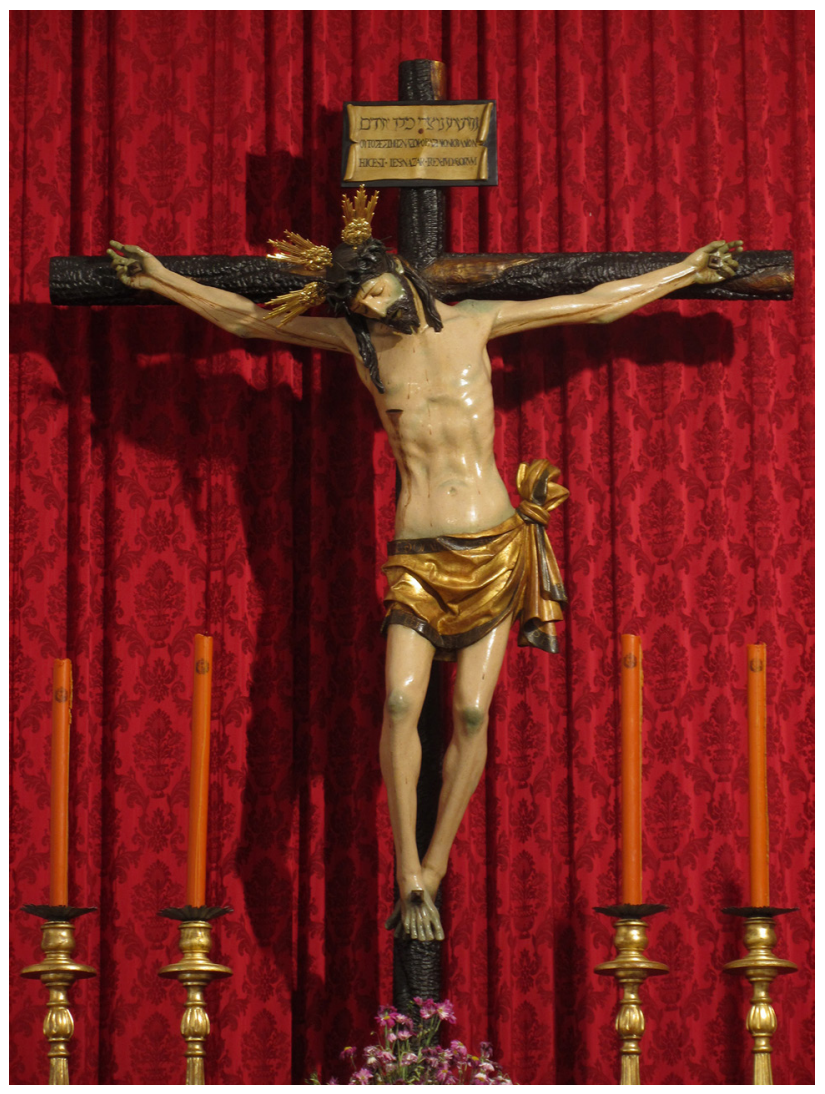

1. Jorge Fernández, Cristo de la Amargura, 1521. Parroquia de San Felipe, Carmona (Sevilla)

1521 y de tamaño natural $(175 \mathrm{~cm})$, siendo en la actualidad la imagen documentada más antigua que desfila procesionalmente en la Semana Santa de Sevilla y su provincia [1]. Sin embargo, no fue concebida con tal finalidad, sino para rematar, junto a las efigies de la Virgen dolorosa y de San Juan evangelista esculpidas también por Jorge Fernández, la viga de la parroquia carmonense de San Felipe, corriendo su policromía a cargo del pintor Juan Sánchez. Tallado en madera de álamo blanco -como la gran mayoría de sus Crucificados-, el tratamiento anatómico incluye detalles de incursión verista en el modelado del estilizado torso, como el pliegue que forma la piel sobre el ombligo, al tiempo que todo el cuerpo se incurva lateralmente, con las enjutas piernas separadas y tensamente delineadas, flexionando hacia el frente la derecha y arqueando la izquierda para buscar el clavo que une los pies. El sudario, estofado en oro y con amplios y profundos pliegues de bordes aristados, presenta

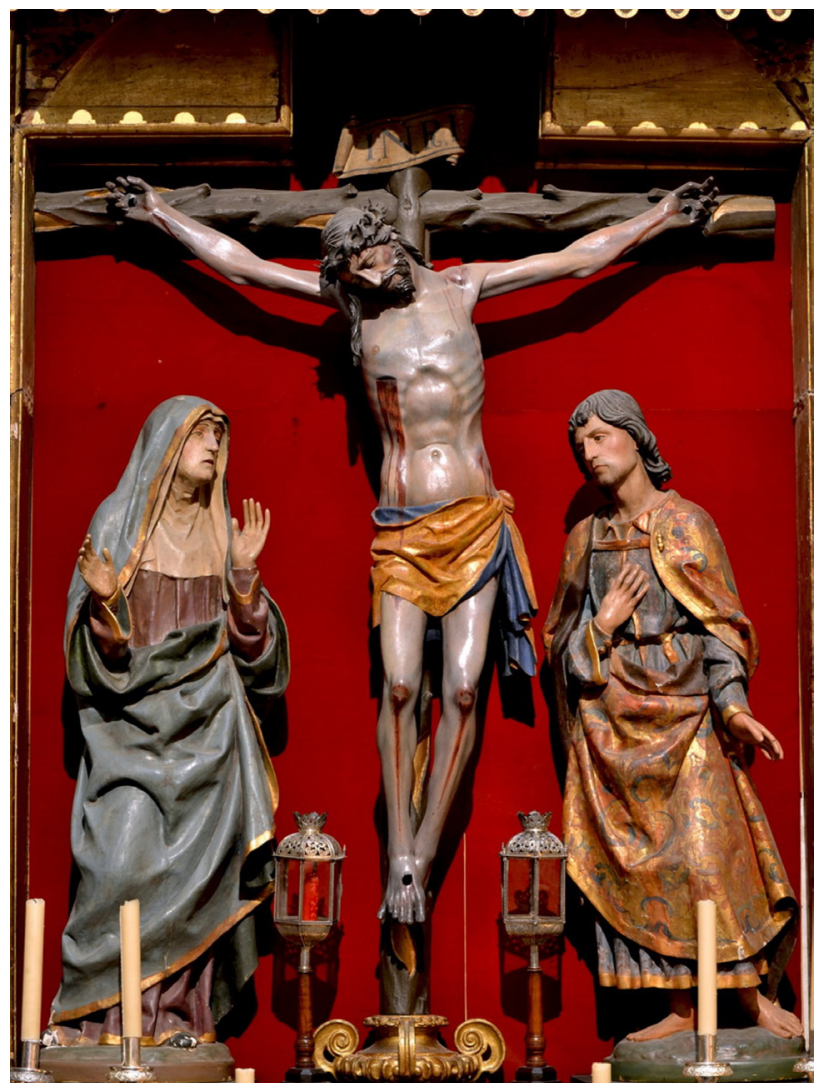

2. Jorge Fernández, Calvario, 1519-1523. Parroquia de Nuestra Señora de la Oliva, Lebrija (Sevilla)

un nudo con caída en la cadera izquierda y una inscripción desarrollada en una doble cenefa por el borde perimetral del paño ${ }^{4}$. Una gruesa y trenzada corona de largas espinas, de un marcado aspecto torturante heredado de la Baja Edad Media, aparece tallada en el mismo bloque craneano, desplomándose la cabeza hacia la derecha. Un largo mechón de pelo, segmentado en dos puntas a diferente altura, desciende de manera exenta a la diestra de su rostro de rasgos finos y expresivamente dolientes, mientras que la barba, de terminación bífida y ahorquillada, configura dos guedejas compactas y picudas.

También De la Villa y Mira lograron documentar, en 1998, la paternidad artística de Jorge Fernández sobre el Cristo, la Dolorosa y el San Juan que conformaban el Calvario de la viga de imaginería del templo de Nuestra Señora de la Oliva de Lebrija [2], conservándose hoy las tres tallas en un retablo de la sacristía parroquial (1998: 55-58). Percibió 
por dicho encargo, que afrontó entre los años 1519 y 1523 , un total de 14.250 maravedíes, 682 más de lo que había cobrado por el grupo anteriormente mencionado de Carmona. En este caso, la policromía corrió a cargo del pintor Alejo Fernández. El Crucificado de Lebrija resulta prácticamente idéntico en sus caracteres morfológicos e iconográficos al de Carmona, con leves distingos en la disposición de la cabellera, que en el caso del Cristo lebrijano oculta parte de la oreja izquierda, mientras que el carmonense la deja al descubierto, cayendo un breve mechón de pelo sobre la clavícula correspondiente.

Los restantes Crucificados que hasta el momento se asignan al quehacer de Jorge Fernández son producto de atribuciones realizadas mediante comparaciones estilísticas y morelianas -y en menor grado, aduciendo cuestiones materiales y técnicas-, de las que citaremos solo aquellas que, a nuestro juicio, han sido formuladas con mayor rigor crítico, aunque con escasa apoyatura documental, con los riesgos que ello conlleva. En este sentido, no parece que pueda obviarse la posibilidad de que algunas de estas y otras muchas obras que se le atribuyen puedan haber sido realizadas por miembros de su obrador y emuladores que asumen modelos creados por el maestro. Es así que podría suceder con Jorge Fernández lo mismo que advertía Joaquín Yarza respecto al escultor tardogótico Alejo de Vahía, que «su modo de hacer es tan claro que enseguida se distingue. Pero con frecuencia es en la obra de su taller y sus seguidores donde se reiteran sus fórmulas» (1989: 377-378).

Comenzaremos este sucinto recuento por el Cristo del Perdón de La Puebla del Río [3], imagen de carácter procesional que se venera en la parroquia de Nuestra Señora de la Granada, cuya vinculación con el citado escultor fue argumentada en 1998 por Roda Peña en razón de las profundas semejanzas de toda índole que presentaba con respecto a los enunciados Crucificados de Carmona y Lebrija (1998: 70-71); fue objeto en 2001 de una profunda restauración por parte de Juan Manuel Miñarro López, que procedió a repolicromarlo en función de los restos que localizó de su encarnadura primitiva, oculta bajo varias capas de película pictórica y de estuco, así como a estofar su paño de pureza, tomando como modelo el del Cristo de la Amargura de Carmona.

Asimismo, resulta pertinente la atribución defendida por Gómez Piñol en 1999 del monumental Crucificado, de

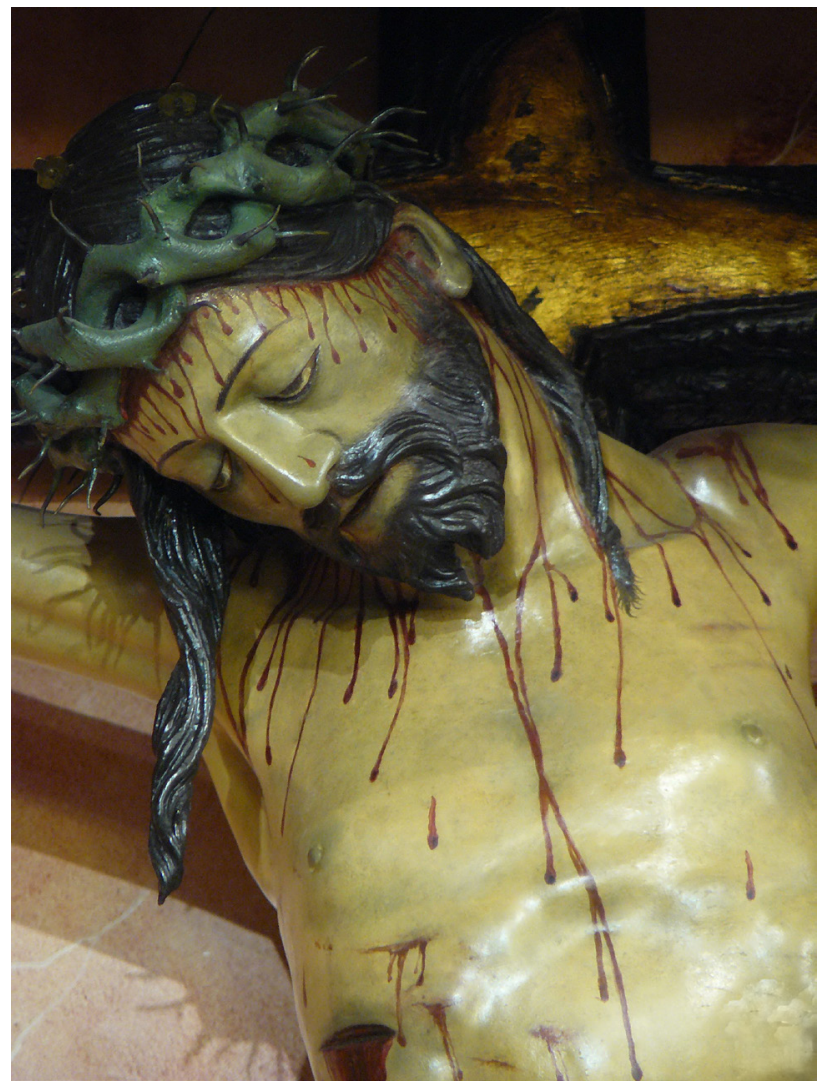

3. Jorge Fernández (atribuido), Cristo del Perdón, hacia 1520. Parroquia de Nuestra Señora de la Granada, La Puebla del Río (Sevilla)

extraordinario vigor plástico, que estuvo situado desde su ejecución en la capilla de San Pablo de la catedral de Sevilla [4], a cuya cripta se trasladaron en 1520 los restos de los caballeros que acompañaron a San Fernando en la conquista de Sevilla (1999: 73-78). Este recinto, a mediados del Seiscientos, amplió su dedicación con la de la Inmaculada, emplazándose entonces el Crucificado en el segundo cuerpo del retablo que preside la denominada Concepción «grande», obra del escultor Alonso Martínez en 1656. Su apabullante presencia corre pareja con una potente morfología de dolorido aspecto físico y espiritual, donde prima el impacto emocional de tono patético, claramente heredado de la ascética medieval. Su abultada y lacerante corona de espinas, así como el sudario de perfiles quebradizos y profundos surcos evocan tipos específicamente germánicos. Resulta proverbial la devoción que esta imagen acaparó durante los siglos XVI y XVII, como viene a demostrarlo, entre otros testi- 


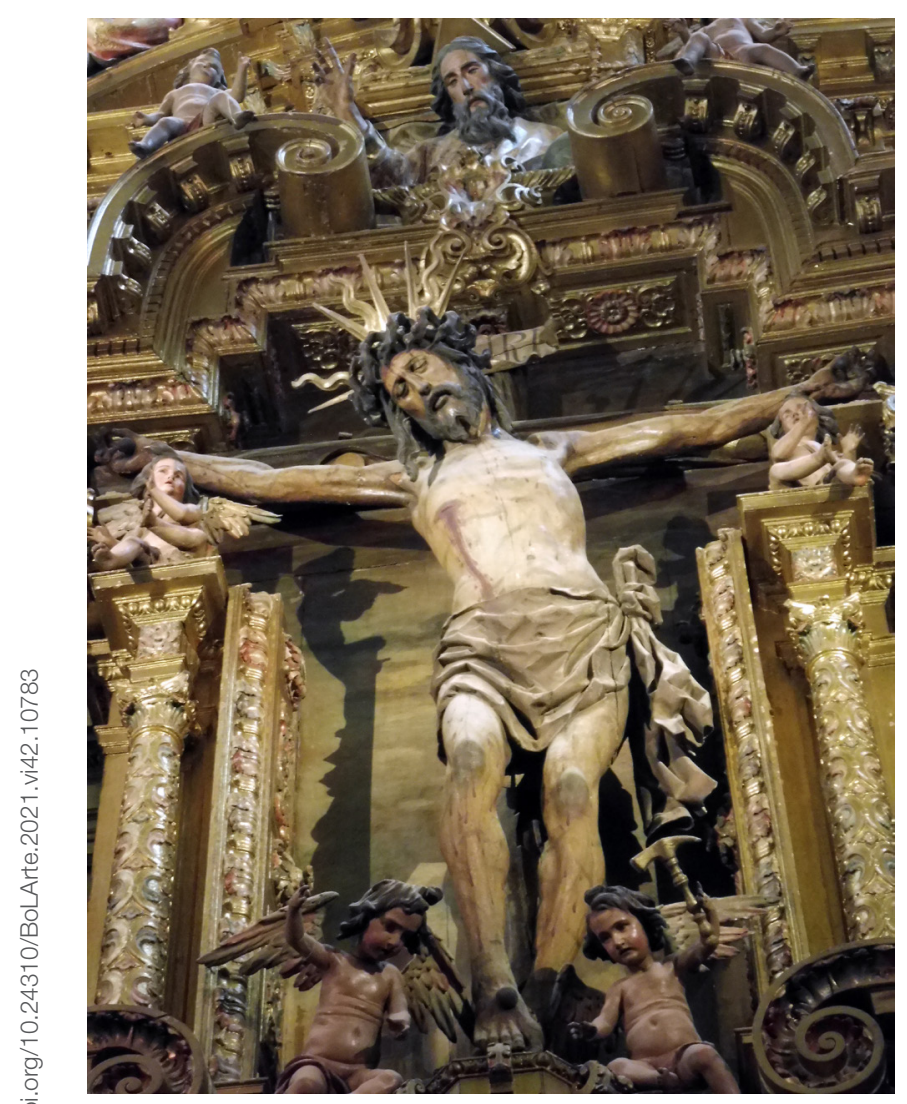

4. Jorge Fernández (atribuido), Crucificado, hacia 1520. Santa Iglesia Catedral, Sevilla monios que han llegado hasta nosotros, el que por iniciativa del canónigo y arcediano de Carmona, Juan Federigui, quien había detectado "que era de summo desconsuelo para el pueblo que el santo Christo de la capilla de San Pablo, estuviese siempre cubierto", el cabildo catedralicio acordara el 27 de junio de 1659 «que los viernes todos y días de fiesta semanalmente esté descubierto» 5 .

Ya en 2003, fueron Domínguez Cubero y Linares Talavera quienes, tras constatar los evidentes paralelismos que podían esgrimirse con algunas de las imágenes ya enumeradas, encajaron en la órbita de Jorge Fernández el Crucifijo de tamaño natural $(185$ cm) que en 1968 había ingresado en el convento de la Inmaculada Concepción de madres dominicas de Jaén, procedente del convento cordobés de Cristo Crucificado, de la misma rama femenina de la Orden de Predicadores (2003: 111-124) 6 .

El ya citado historiador Fernando de la Villa Nogales y el restaurador Juan Carlos Castro Jiménez difundieron en febrero de 2012, a través de la prensa escrita y medios cibernéticos (Mallado, 2012: 30), su convicción de haber hallado dos nuevos Crucificados adscribibles a la gubia de Jorge Fernández, que después fueron mencionados en una publicación científica por el profesor Palomero (2013: 43) y estudiados con mayor extensión por Salvador Hernández (2014: 257-259). Hablamos, por un lado, del Cristo de la Antigua o

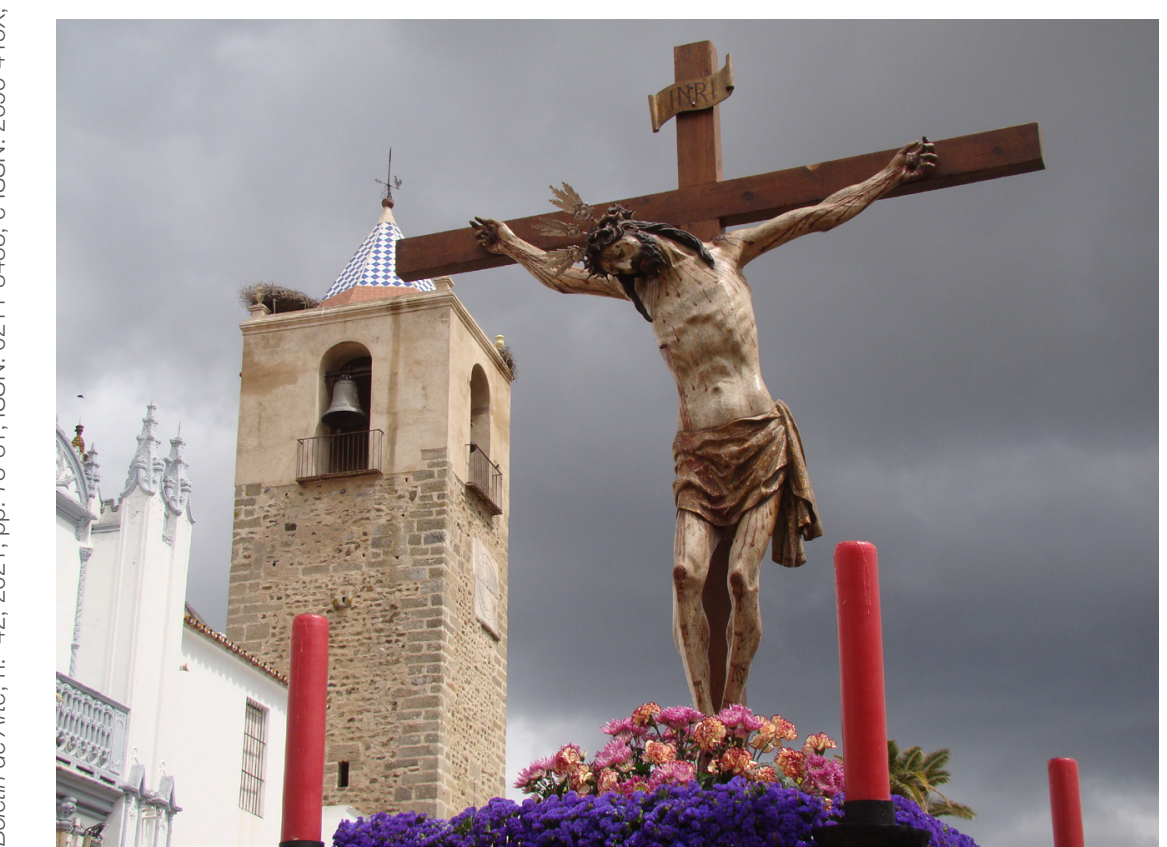

5. Jorge Fernández (atribuido), Cristo del Perdón, hacia 1520. Parroquia de Santa Catalina, Fregenal de la Sierra (Badajoz) 
del Castillo, que recibe culto en la ermita del Santo Cristo de Espera (Cádiz); de poco más de un metro de altura, tallado en álamo y fechable hacia 1525, resulta notoria la verticalidad de su figura, que recibe un tratamiento anatómico de contextura más carnosa que en ejemplos anteriores ${ }^{7}$. Y por otro, del Cristo del Perdón, llegado a la parroquia de Santa Catalina de Fregenal de la Sierra (Badajoz) desde el extinguido convento de Santa Clara de esta misma localidad pacense [5]. De tamaño natural y esculpido asimismo en madera de álamo, en la actualidad es titular de una cofradía de penitencia que sale en procesión en la tarde del Viernes Santo; su silueta acusa el arqueamiento característico de buena parte de sus Crucificados, que aquí se muestra incluso más pronunciado ${ }^{8}$.

En 2018, Roda Peña presentó una nueva asignación razonablemente segura al quehacer plástico de Jorge Fernández (2018: 19-21). Es el Crucificado titulado del Amor, de un metro de alto, que preside, enmarcado por un retablito dieciochesco, el antiguo oratorio del monasterio de mercedarias descalzas de la Encarnación de Osuna, dependencia que hoy forma parte del museo conventual y se conoce como saleta de los Niños [6]. Tanto su tipo físico y expresión facial, como su tratamiento anatómico y disposición corporal proporcionan inequívocos puntos de contacto con los Cristos mencionados anteriormente, y muy en particular con el de la Amargura de Carmona, pudiéndose fechar de manera provisional en la década de 1520.

El Cristo carmonense vuelve a ser el principal e ineludible referente para ofrecer en estas breves líneas la primicia de una atribución inédita a Jorge Fernández. Este Crucificado que ahora centra nuestra atención ha pasado completamente inadvertido hasta el presente para la historiografía artística, lo que pudiera justificarse por el hecho de cobijarse entre los muros de la clausura del monasterio hispalense de clarisas de Santa María de Jesús [7], aunque en realidad procede de la sala reglar del extinto convento de Santa Clara ${ }^{9}$, cuya comunidad, junto a parte de sus bienes muebles, se reunió en agosto de 1996 con la anterior, de su misma rama femenina de la orden franciscana ${ }^{10}$. Es un Crucifijo de pequeño formato $(74 \mathrm{~cm})$, que está siendo oportunamente restaurado en 2020 por Jaime Hernández Benítez, pues la pieza se encontraba afectada de graves daños, tanto en su soporte -atacado por los xilófagos, con los brazos desensamblados y pérdidas volumétricas-, como en su policromía

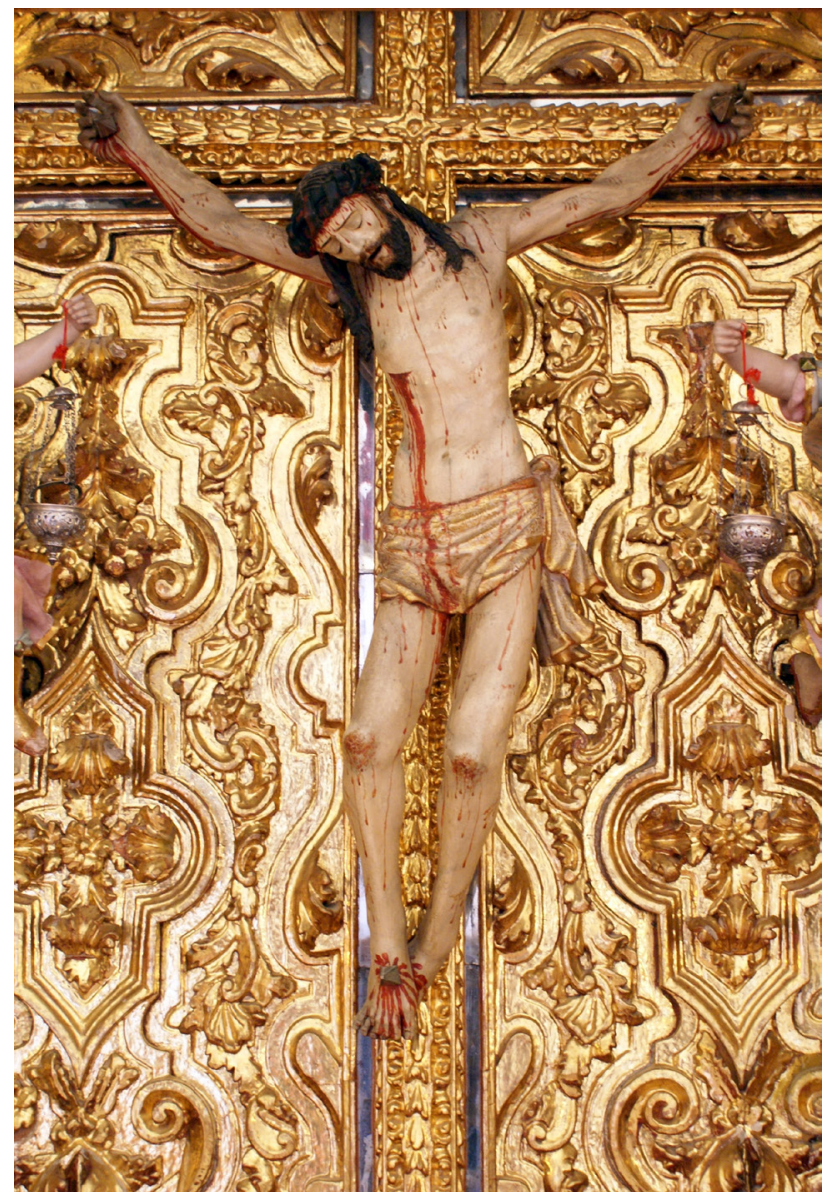

6. Jorge Fernández (atribuido), Cristo del Amor, década de 1520. Monasterio de la Encarnación, Osuna (Sevilla)

visible [8]; esta última, aun no siendo la original, se ha respetado, habiéndose de recuperar, eso sí, el estofado subyacente de su corona de espinas y paño de pureza ${ }^{11}$.

El Cristo se encuentra fijo mediante tres clavos a una cruz arbórea de gajos, cuyo extremo superior se remata con una aparatosa cartela dorada, que adopta el formato de una tarja vegetalizada seiscentista, conteniendo el acrónimo INRI. Resultan palmarios los coincidentes grafismos que a nivel técnico, formal y expresivo pueden señalarse en este Crucificado, que permiten emparentarlo de manera solvente con otras creaciones de este mismo tema debidas a Jorge Fernández. Es el caso de la cabeza vencida hacia la diestra, ceñida por una gruesa corona tallada sobre el propio cráneo, de la que apenas ha sobrevivido alguna de sus largas y punzantes púas pegada a la frente que junto a 


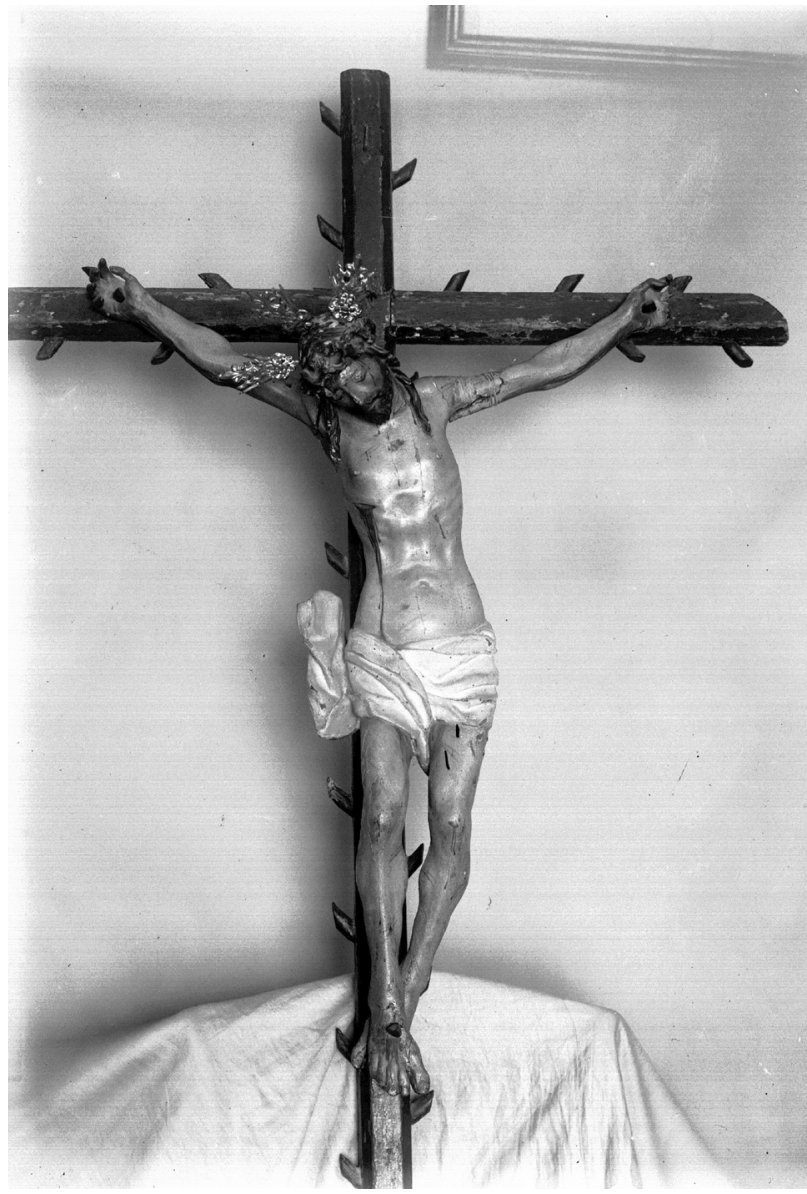

7. Jorge Fernández (atribuido), Crucificado, hacia 1520. Monasterio de Santa María de Jesús, Sevilla. Foto: José María González-Nandín y Paúl 1924, Fototeca Laboratorio de Arte de la Universidad de Sevilla, n. ${ }^{\circ}$ de registro 3-2465

otras, ya perdidas, simulaban atravesar la epidermis. Otros rasgos tendentes a incidir en la atormentada faz de este Cristo sufriente, cuyo prototipo físico es compartido con el de los restantes Crucificados adjudicados a este mismo escultor, serían los ojos de trazado oblicuo, párpados entornados y entristecida mirada, que se compadece muy bien, comunicativamente hablando, con el amargo rictus que describen sus labios entreabiertos, a través de los cuales resulta posible apreciar la talla de los dientes. Tanto la firme nariz, de contundente apariencia, como la barba corta y nítidamente bifurcada, han sido contempladas en casos precedentes. El alongado mechón de pelo que cae, suelto, por la derecha, junto al que en el lado contrario desciende pegado por el cuello en tensión, hasta sobrepasar

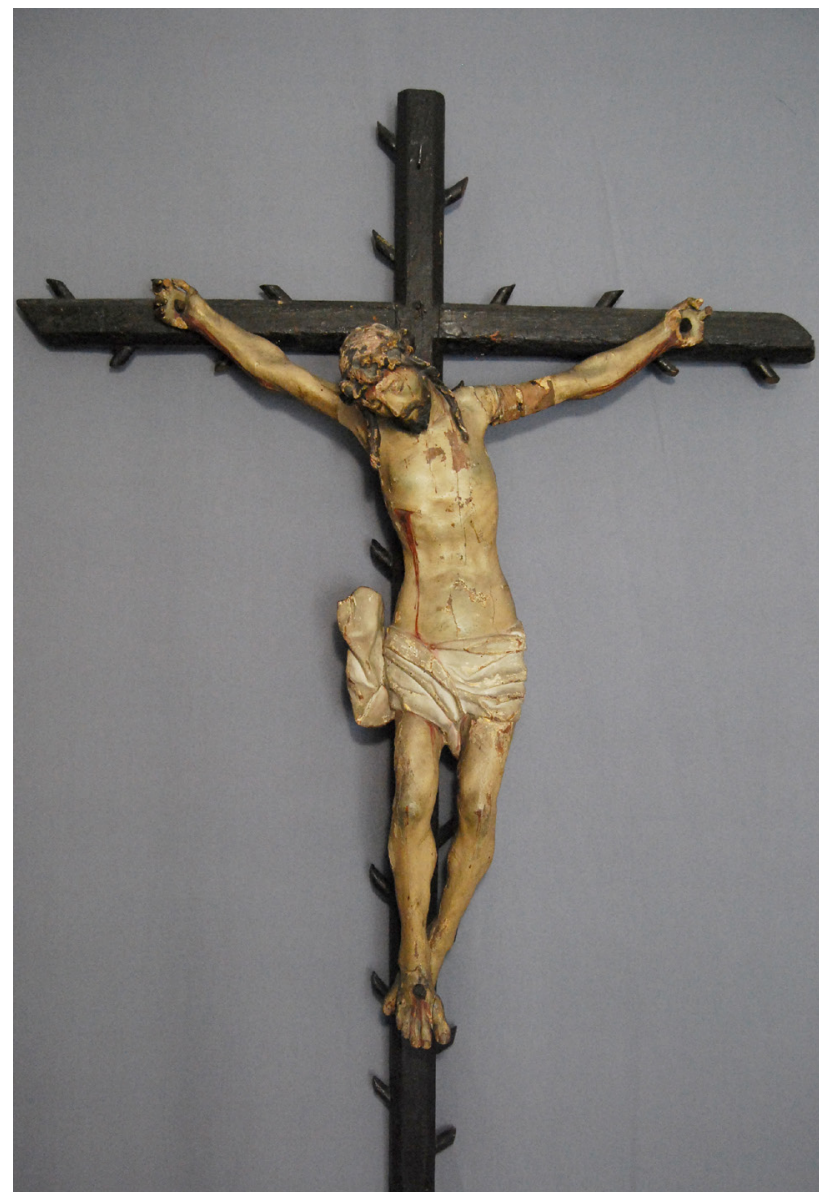

8. Jorge Fernández (atribuido), Crucificado, hacia 1520. Monasterio de Santa María de Jesús, Sevilla

el nivel de la clavícula, constituyen otro signo identificativo de la personal versión que nos brinda Jorge Fernández de la testa del Redentor en estas representaciones suyas de la crucifixión [9].

La configuración de su torso resulta, asimismo, muy característica en su modelo de Crucificado, con el volumen de su caja torácica algo abombado y las costillas someramente señaladas. Resulta perceptible el estrechamiento de la cintura que precede al ensanche de las caderas, abultándose el abdomen bajo el ombligo. En general, se visibiliza un embrionario naturalismo en la flexible apariencia de la piel y en la armónica articulación de los miembros anatómicos, repitiéndose esa inclinación ya vista de todo el cuerpo, que describe un leve arco hacia su izquierda, recordando la com- 


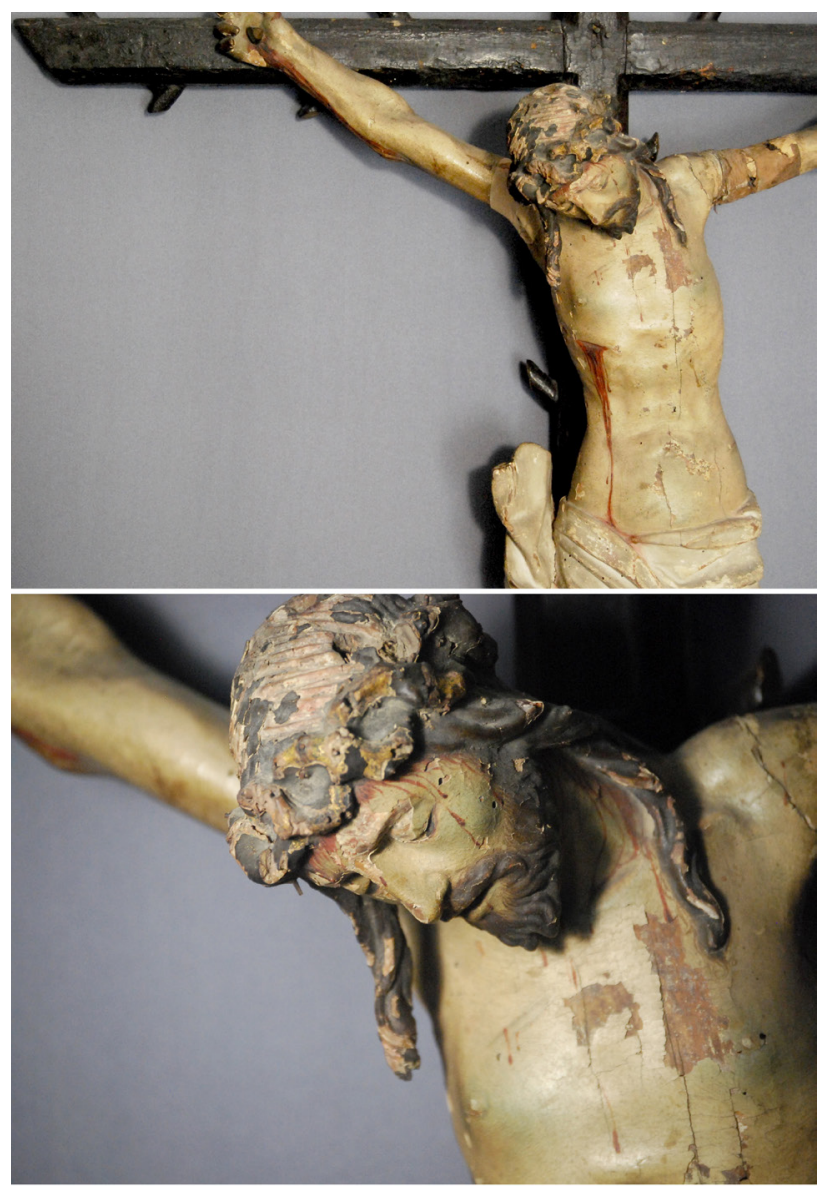

9. Jorge Fernández (atribuido), Crucificado (detalles), hacia 1520. Monasterio de Santa María de Jesús, Sevilla

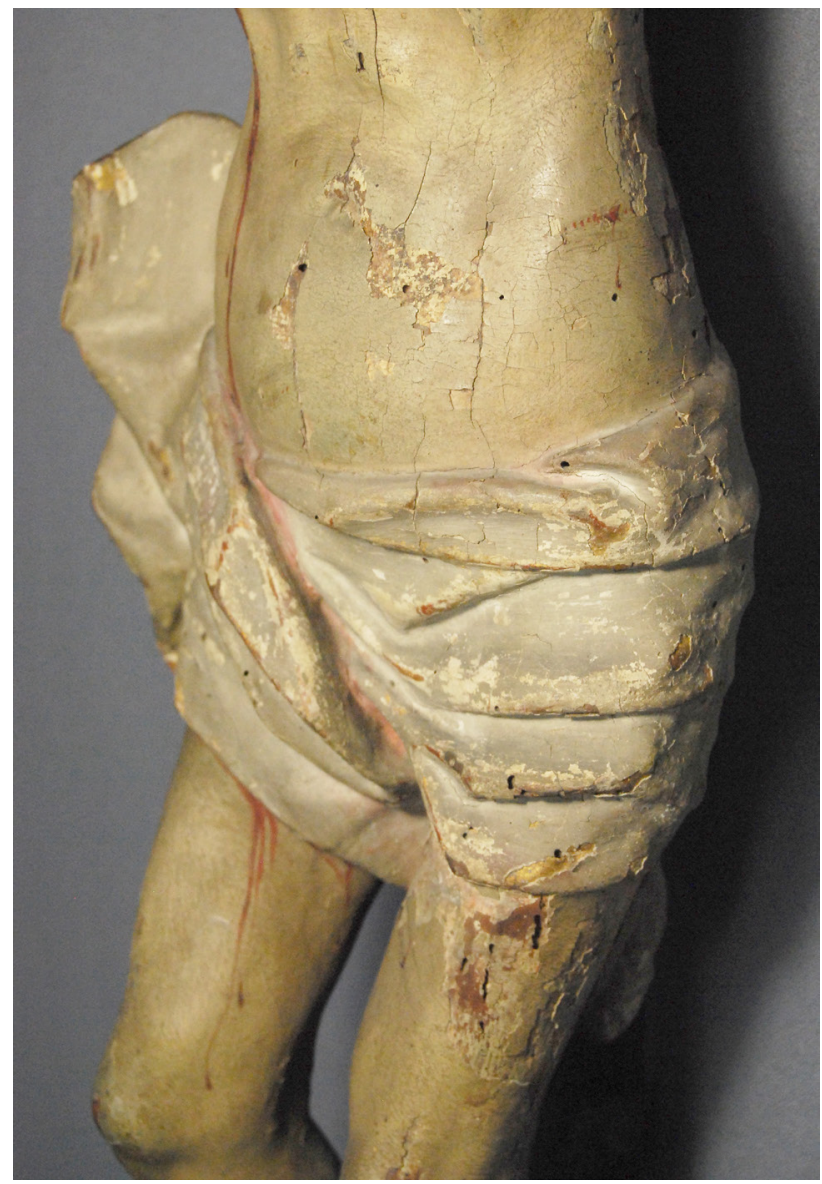

10. Jorge Fernández (atribuido), Crucificado (paño de pureza), hacia 1520. Monasterio de Santa María de Jesús, Sevilla posición que manifiestan tantos Crucifijos de marfil. El paño de pureza es corto y se cruza en el centro, advirtiéndose una cierta dureza en el tratamiento de los pliegues, ascendiendo un fragmento de tela, sin excesivo vuelo, por el costado derecho [10].

La imagen del monasterio sevillano de Santa María de Jesús viene, por consiguiente, a incrementar esta creciente nómina de Crucificados vinculables a Jorge Fernández o a su taller, que obedecen a un modelo ciertamente muy personal, pero que guarda similitudes diversas y siempre parciales o fragmentarias con otras efigies de la misma iconografía plasmadas por pintores y escultores de los antiguos Países Bajos y de Alemania, desde mediados del siglo XV hasta las décadas iniciales del XVI ${ }^{12}$.

\section{Notas}

1 Su llegada a Sevilla en 1508 se vio precedida de una puntual estancia en 1505, como lo acredita el asiento registrado en un libro de fábrica de la catedral, por el que se pagaban mil maravedíes «a jorge fernández alemán para el camino quando vino a concertarse de la ymaginería de la yglesia». Es este, por cierto, el único asiento documental publicado hasta el momento en que se le identifica como «alemán», haciéndose derivar de ello su ascendencia germana o flamenca. Giménez, 1927: 19.

2 A la mejor definición de su biografía, estilo y producción escultórica han contribuido últimamente Palomero, 2013: 41-45; Hernández, 2014: 215-267; Herrera, 2014: 315-345. 
3 Desaparecido o en paradero ignoto se encuentra el «crucifijo de bulto» que el dominico fray Pedro de Córdoba se llevó a la isla de La Española en 1513, por cuya talla se pagaron a Jorge Fernández 4.000 maravedíes y otros tantos a Alejo Fernández por su policromía. Ladero, 2008: 389 . Lo mismo sucede con el Crucificado concertado el 12 de septiembre de 1515 para el oratorio de Pedro Ramírez, vecino de Guadalcanal. Gestoso y Pérez, 1908: 103. Tampoco se han localizado el "cruçifixo grande de bulto de madera» y la «ymagen de nuestra señora con un niño ins» que fray Juan de Chaves se llevaría a Santa Marta (Colombia) en 1533, por las que el tesorero de la Casa de la Contratación abonó a «jorge hernández entallador» la suma de 6.000 maravedíes; los 6.100 maravedíes de su policromía y estofado se liquidaron al pintor Antón Sánchez de Guadalupe. Gestoso y Pérez, 1899: 395. En su testamento del 14 de febrero de 1535, Jorge Fernández declaraba estar adeudándosele 4.600 maravedíes del resto de un «cruçifixo con un Sant Juan e la María» que hizo para la iglesia de San Salvador de Carmona. Palomero Páramo, 2013: 44.

4 La configuración actual de dicha lazada se debe a la restauración practicada por el imaginero Francisco Buiza Fernández en 1970, quien también talló el mechón de cabello que cae por el lado derecho del rostro, en sustitución de otro anterior que estaba carcomido por los xilófagos. Por otro lado, en la memoria final de la intervención del Cristo llevada a cabo por el IAPH en 2011, se duda que la inscripción del sudario sea, al menos en su integridad, de época original. Comenzando por la espalda, pueden leerse las siguientes letras en su borde superior: OVTNCOINT NPJASI; en el inferior: SIVA ACELERA VTERVAS. En el nudo aparece: TIBI SOL PECCAVI. En el borde superior del frente: IN TE DOMINE PERAV, y en el inferior: INTERNU ET IISVSTIC.

5 Archivo de la Catedral de Sevilla (ACS), Fondo Capitular, Secretaría, Autos Capitulares, Leg. 65 (7113), Autos de 1659-1660, f. 49. Agradezco la referencia documental al Dr. D. Álvaro Cabezas García.

6 Este Crucificado fue restaurado en 2002 por Jacinto Linares Talavera, quien ofrece el informe de su intervención en este artículo.

7 Cuenta con una monografía editada por Garrucho Jurado, 2017. La escultura ha sido restaurada por Juan Carlos Castro Jiménez en 2016.

8 En abril de 2019 culminó su restauración por Miguel Ángel Ojeda Zarallo en los talleres del Centro de Conservación y Restauración de Bienes Culturales de la Junta de Extremadura. Fernando de la Villa estima que pudiera datarse en torno a 1529, mientras que Salvador Hernández piensa en una cronología sensiblemente anterior, habida cuenta "de la mayor carga arcaizante de la figura extremeña en comparación con la de Carmona». Hernández, $2014: 259$.

9 Tal localización aparece reflejada en la ficha catalográfica de la fotografía tomada por José María González-Nandín y Paúl el 18 de julio de 1924, que se conserva en la Fototeca Laboratorio de Arte de la Universidad de Sevilla, con el número de registro 3-2465. Este Crucificado presidía, en el convento de Santa Clara, el espacioso vestíbulo situado tras atravesar la puerta reglar, que constituía el acceso a la clausura propiamente dicha.

10 Agradezco a sor Lucía, abadesa del monasterio de Santa María de Jesús de Sevilla, las facilidades otorgadas para el estudio de este Crucificado.

11 Mi gratitud a Jaime Hernández Benítez, conservador y restaurador de bienes culturales, por haberme permitido acceder al informe diagnóstico para la intervención de este Cristo, cuya cruz alcanza una altura de $132 \mathrm{~cm}$.

12 Pueden consultarse a este respecto los estudios críticos contenidos en AA. W., 2003. AA. W., 2016.

\section{Bibliografía}

AA. W. (2003), Lumen Canariense. El Cristo de la Laguna y su tiempo, vol. I, Ayuntamiento de San Cristóbal de La Laguna, Consejería de Educación, Cultura y Deportes del Gobierno de Canarias y Servicio de Publicaciones de la Caja General de Ahorros de Canarias, San Cristóbal de La Laguna.

AA. W. (2016), Últimos fuegos góticos. Escultura alemana del Bode Museum de Berlín, Ministerio de Educación, Cultura y Deportes, Madrid. DE LA VILLA NOGALES, Fernando y MIRA CABALLOS, Esteban (1993), «El Crucificado de la Hermandad de la Amargura de Carmona: obra de Jorge Fernández Alemán (1521)", Atrio, n. ${ }^{\circ}$, pp. 7-13.

DE LA VILLA NOGALES, Fernando y MIRA CABALLOS, Esteban (1998), «Un nuevo Crucificado documentado del insigne escultor del Quinientos Jorge Fernández Alemán», Boletín de las Cofradías de Sevilla, n. ${ }^{4}$ 469, pp. 55-58.

DOMíNGUEZ CUBERO, José y LINARES TALAVERA, Jacinto (2003), «Un Cristo de Jorge Fernández Alemán en Jaén», Boletín del Instituto de Estudios Giennenses, n. ${ }^{\circ} 185$, pp. 111-124.

GARRUCHO JURADO, Manuel (2017), Santo Cristo de la Antigua. Espera. Historia, arte y veneración de una imagen, Ayuntamiento de Espera, Espera.

GESTOSO Y PÉREZ, José (1899 y 1908), Ensayo de un Diccionario de los artífices que florecieron en Sevilla desde el siglo XIII al XVIII inclusive, vols. I y III, Oficina de La Andalucía Moderna, Sevilla.

GIMÉNEZ FERNÁNDEZ, Manuel (1927), «El Retablo mayor de la Catedral de Sevilla y sus artistas», en Documentos para la Historia del Arte en Andalucía, vol. I, Universidad de Sevilla, Facultad de Filosofía y Letras, Sevilla, pp. 9-55.

GÓMEZ PIÑOL, Emilio (1999), «Sentimiento religioso e imágenes del Crucificado en el arte hispanoamericano del siglo XVl», en LÓPEZ GUTIÉRREZ, Antonio y RODA PEÑA, José (coms.), Signos de Evangelización. Sevilla y las Hermandades en Hispanoamérica, Fundación El Monte, Sevilla, pp. 63-94.

HERNÁNDEZ GONZÁLEZ, Salvador (2014), La escultura en madera del Gótico final en Sevilla. La sillería del coro de la Catedral de Sevilla, Diputación de Sevilla, Sevilla. 
HERRERA GARCÍA, Francisco Javier (2014), «Flandes-Canarias, a través de los talleres sevillanos. Un encargo escultórico a Sevilla a comienzos del XVI", en RODRÍGUEZ MORALES, Carlos (ed.), Homenaje a la profesora Constanza Negrín Delgado, Instituto de Estudios Canarios, La Laguna, pp. 315-345.

LADERO QUESADA, Miguel Ángel (2008), «Presencia eclesiástica en Indias según los libros de cuentas de la Casa de la Contratación. 15031521», Anuario de Estudios Atlánticos, n. ${ }^{\circ}$ 54-I, pp. 371-401.

MALLADO, A. (2012), «El »padre« de los crucificados sevillanos», ABC de Sevilla, 4 de febrero, p. 30.

PALOMERO PÁRAMO, Jesús (2013), «El entallador Jorge Fernández: las arras en Córdoba y el testamento en Sevilla», en ZALAMA RODRíGUEZ, Miguel Ángel y MOGOLLÓN CANO-CORTÉS, Pilar (coords.), Alma Ars. Estudios de Arte e Historia en homenaje al Dr. Salvador Andrés Ordax, Universidad de Valladolid, Valladolid, pp. 41-45.

RODA PEÑA, José (1998), «El Crucificado en la escultura procesional sevillana», en SÁNCHEZ HERRERO, José, GARCÍA DE LA CONCHA DELGADO, Federico y RODA PEÑA, José (dirs.), Crucificados de Sevilla, vol. I, Ediciones Tartessos, Sevilla, pp. 54-91.

RODA PEÑA, José (2015), "Crucificados escultóricos sevillanos entre el Renacimiento y el primer naturalismo barroco", en En torno al Réquiem de Tomás Luis de Victoria. Ensayos sobre arte, música y pensamiento, Instituto de la Cultura y Artes del Ayuntamiento de Sevilla, Sevilla, pp. 51-68.

RODA PEÑA, José (2018), «Desde Jorge Fernández a Juan de Mesa: Un siglo de crucificados en la escultura sevillana», en DOBADO FERNÁNDEZ, Juan (coord.), Martínez Montañés y el Cristo de los Desamparados. Entre Pablo de Rojas y Juan de Mesa, Editorial Samarcanda, Sevilla, pp. 11-47.

YARZA LUACES, Joaquín (1989), «El Crucificado en Alejo de Vahía: una nueva imagen», Boletín del Seminario de Estudios de Arte y Arqueología, n. ${ }^{\circ 5}$, pp. 376-380. 